\title{
The Structural Perspective on CDK5
}

\author{
Marina Mapelli Andrea Musacchio \\ Structural Biology Unit, Department of Experimental Oncology, European Institute of Oncology, Milan, Italy
}

\section{Key Words}

Cyclin-dependent kinase 5 - Cyclin-dependent kinase 2 . Alzheimer's disease - Neuronal cyclin-dependent kinase 5 activator $\cdot$ p25 · p39 - p35 - Amyotrophic lateral sclerosis

\begin{abstract}
Cyclin-dependent kinase 5 (CDK5) plays an essential role in the development of the central nervous system during mammalian embryogenesis. In the adult, CDK5 is required for the maintenance of neuronal architecture. Its deregulation has profound cytotoxic effects and has been implicated in the development of neurodegenerative diseases such as Alzheimer's disease and amyotrophic lateral sclerosis. In this review, we concentrate on the regulation of CDK5 activity, privileging a structural perspective based on a decade of structural analyses of different members of the CDK family, including CDK2 and CDK5. We review the activation mechanism of CDK5 and discuss its differences and similarities with that of CDK2 and of the other members of the CDK family.
\end{abstract}

Copyright ( $\odot 2003$ S. Karger AG, Basel

\section{Introduction}

Modification of protein substrates on serine, threonine or tyrosine residues by the addition of a phosphate group is the baton protein kinases use to conduct each and every orchestration of biology. Phosphorylation influences the interaction of proteins with other proteins, nucleic acids and lipids; it controls protein localization and stability; it controls enzyme kinetics and the progression of biological reactions. As a dissonance in this harmony, phosphorylation gains an additional share of attention because its deregulation has critical adverse effects on human health, playing a role in neurodegenerative disorders, tumor progression and an array of other ailments. This review focuses on a member of the family of cyclin-dependent kinases (CDKs) known as CDK5, whose activity has been implicated in neural development, maintenance of adult neuronal architecture and neurodegeneration [1]. Other contributions in this volume will be concerned with the normal function of CDK5 and with the pathological outcomes of its deregulation, and we will avoid discussing functional issues here. Rather, we will concentrate on the structural aspects of CDK5 regulation, a line of investigation that will hopefully have profound effects on our ability to control CDK5 activity when it runs amok. In the course of the last decade, the availability of an array of structures of active and inactive kinases has provided solid foundations to understand the mechanism of kinase activation. This progress has been thoroughly discussed in a couple of excellent recent reviews [2,3] and will only be summarized here as a necessary introduction to our investigation of the properties of CDK5.

\begin{tabular}{ll}
\hline KARGER & ( 2003 S. Karger AG, Basel \\
Fax +4161306 1234 $34-862 X / 03 / 0125-0164 \$ 19.50 / 0$ \\
$\begin{array}{l}\text { E-Mail karger@karger.ch } \\
\text { www.karger.com }\end{array}$ & $\begin{array}{l}\text { Accessible online at: } \\
\text { www.karger.com/nsg }\end{array}$
\end{tabular}

Andrea Musacchio

Structural Biology Unit, Department of Experimental Oncology

European Institute of Oncology, Via Ripamonti 435

IT-20141 Milan (Italy)

Tel. +3902574 489829, Fax +3902574 489851, E-Mail amusacch@ieo.it 
Fig. 1. Ribbon diagram of the CDK5-p25 complex showing the many different regions and segments that are discussed in the text [28]. The CDK5 kinase (left) is composed of a small N-terminal lobe (light blue) and a C-terminal helical lobe (dark blue). The $\alpha \mathrm{C}$ helix (PSAALRE) is colored dark green. The glycine-rich loop, at the front of the structure, is colored pink. The activation loop is colored magenta. The p 25 moiety consists of a CBF (yellow), the $\alpha \mathrm{NT}$ helix (gray) and 2 $\mathrm{C}$-terminal helices (orange). $\mathrm{N}$ and $\mathrm{C}$ represent the $\mathrm{N}$ and $\mathrm{C}$ termini, respectively. The structure represents a complex of CDK5-p25 with roscovitine (green), a CDK inhibitor, whose backbone is visible in the ATP-binding site in the catalytic cleft at the interface between the $\mathrm{N}$ and $\mathrm{C}$ lobes [M.M. and A.M, unpubl. results]. Figures 1 and 2 were created with program PyMOL [DeLano, W.L.: The PyMOL Molecular Graphics System (2002) on http://www.pymol.org].

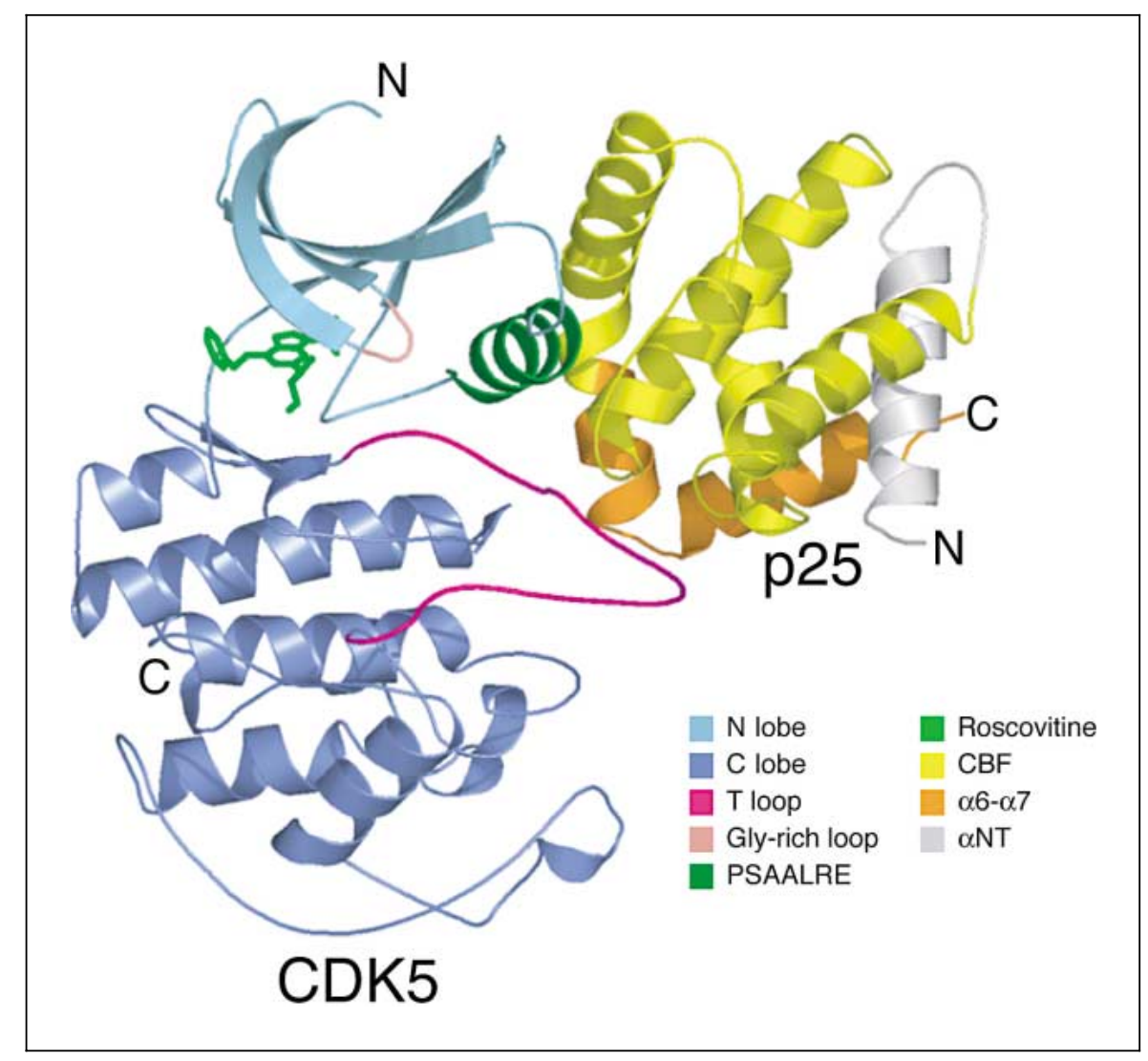

\section{Mechanisms of Kinase Activation: A Primer}

Protein kinases populate one of the largest gene families in the eukaryotic world, representing $2-3 \%$ of the human genome [4-6]. Most protein kinases belong to a single superfamily containing a eukaryotic protein kinase (ePK) catalytic domain, which may be flanked by different additional domains often involved in the regulation of the neighboring kinase domain $[4,6]$ (an updated webbased service on kinase sequences is available at http:// kinase.ucsf.edu/ksd). The crystal structure of the cAMPdependent protein kinase [7], the first to be reported for an ePK domain, revealed a bilobar structure, with an Nterminal domain ( $\mathrm{N}$ lobe) of approximately 85 residues that is mainly $\beta$-sheet in structure (but also containing the well-conserved $\alpha \mathrm{C}$ helix), a predominantly $\alpha$-helical C-terminal domain (C lobe) of approximately 170 amino acids and a deep ATP-binding cleft between the two lobes [2,3]. With small variations, this arrangement is found in all ePK domains, including CDK5 (fig. 1).

ePKs are molecular switches whose on and off states share for the most part similar structural features. Certain segments, however, adopt significantly different conformations in the on and off states, and these structural changes dramatically alter the activation state of the kinase. In this respect, the mechanism of kinase activation can be viewed as a regulated folding process of the ePK domain. This process evolves into a unique active conformation competent for phosphate transfer so that the structures of active kinases tend to be significantly more alike than those of the inactive counterparts [2, 8]. A key control element is the activation loop, a flexible stretch of approximately 20 residues located centrally at the interface between the $\mathrm{N}$ and $\mathrm{C}$ lobes (fig. 1). The $\mathrm{N}$ and $\mathrm{C}$-terminal portions of the activation loop are critically involved in the positioning of ATP and in the recognition of substrates, respectively. The activation loop is often disordered when kinases are inactive, or it adopts a stable conformation that operates a steric blockade to the active site [2, 3, 9]. In active kinases, however, the activation loop is restrained into an extended, open conformation that creates a platform for the interaction of kinases with substrates, contributing to the specificity of substrate recognition, and stabilizing the transition state of the 
phosphotransfer reaction. Although inactive kinases are usually capable of binding ATP, the position of the phosphates of ATP in the active site is incompatible with phosphotransfer activity (see for instance Schulze-Gahmen et al. [10] and De Bondt et al. [11]). Another hallmark of activation, therefore, is the restructuring of the $\mathrm{N}$ lobe to generate a conformation that allows proper positioning of ATP in the kinase active site (fig. 1).

\section{The Structural Bases of CDK Regulation}

An array of different mechanisms controls the conformational changes required for the transition from the inactive to the catalytically competent conformation of ePK domains [2]. Here we concentrate on CDKs, an ePK subfamily of serine/threonine kinases displaying exquisite selectivity towards substrates containing a proline residue at the $\mathrm{P}_{+1}$ position relative to the phosphate acceptor (for which reason these kinases are referred to as "prolinedirected') $[8,12,13]$. Several CDKs show a dual mechanism of activation. One step consists of the binding of a family of homologous protein activators known as cyclins (a name that reflects variations in the abundance of these proteins during the cell cycle). A second step consists of the phosphorylation of the activation loop at a conserved threonine residue ( $\mathrm{Thr}^{160}$ in CDK2). Execution of both regulatory steps (possibly in no defined order) is required for full CDK2 activation $[8,13,14]$.

A dual mechanism of activation based on cyclin binding and phosphorylation of the activation loop on $\mathrm{Thr}^{160}$ pertains to other members of the CDK family, including CDK1, CDK4 and CDK6 [15]. This model of activation, however, does not apply to CDK5, despite sequence identities running near $60 \%$ for CDK2-CDK 5 pairs in different species. In fact, CDK5 binds to cyclins D and E, but these fail to ignite its kinase activity $[16,17]$. Instead, CDK5 activity is triggered by $\mathrm{p} 35^{\text {ncka }}$ and $\mathrm{p} 39^{\text {nckai }}$ (p35 and p39 from now on), homologous proteins whose expression is limited to neurons and to a few other cell types [18-21]. Furthermore, CDK5 does not seem to be activated by phosphorylation of the activation loop, even if this contains a potential site of phosphorylation $\left(\operatorname{Ser}^{159}\right.$, equivalent to $\mathrm{Thr}^{160}$ of CDK2) [22].

These differences in activation mechanism can now be explained based on a wealth of high-resolution structural investigations of CDK family members in different states of activation. The structure of CDK2, the CDK family member whose architecture and catalytic properties have been most widely studied, has been determined with and without cyclin A [11,23], and each of these two states has also been analyzed in the presence of phosphorylated $\mathrm{Thr}^{160}[24,25]$. A structure of phospho-CDK2-cyclin-A has also been determined in the presence of ATP and a peptide substrate [26]. These structural analyses have been complemented with elegant investigations on the kinetic properties of the same chemical species, providing a rich intellectual framework to understand the mechanisms of CDK2 activation (reviewed in Lew [27]). The recently reported crystal structure of the unphosphorylated CDK5-p25 complex (p25 is a proteolytic product consisting of residues 99-307 of p35 and containing the essential CDK5 activation domain) allowed an analysis of the differences in the mechanisms of activation of CDK2 and CDK5, finally shedding light onto many of CDK5's unusual properties [28].

Cyclin A binding to CDK2 remodels the kinase $\mathrm{N}$ lobe to allow the correct orientation of ATP [23]. Cyclin A pushes the $\alpha \mathrm{C}$ helix into the active site, triggering the interaction between $\mathrm{Lys}^{33}$ and $\mathrm{Glu}^{51}$ that is required to position the $\alpha$ - and $\beta$-phosphates of ATP. (The $\alpha \mathrm{C}$ helix takes the name of PSTAIRE helix in CDK2 and PSAALRE in CDK5, based on the polypeptide sequence of the $\alpha \mathrm{C}$ helix in the 2 kinases, reported in single-letter amino acid code. $\mathrm{Glu}^{51}$ is the last residue of the PSTAIRE sequence.) The region of the activation loop around the conserved Asp-Phe-Gly motif is also locked by cyclin A into a conformation that supports the function of this motif in the orientation of the $\gamma$-phosphate of ATP via a magnesium ion. Finally, binding of cyclin A to CDK2 triggers a partial restructuring of the activation loop that alleviates the steric blockade to the active site observed in apo-CDK2 [11, 23].

Cyclin binding, however, is insufficient to cause full activation of CDK2, because a further round of remodeling of the activation loop is still required. This is triggered by the phosphorylation of $\mathrm{Thr}^{160}$ by CDK-activating kinase [14]. Thr ${ }^{160}$ resides within the activation loop, which roughly encompasses residues $145-165$ of CDK2. Its phosphorylation causes the activation loop to adopt a conformation that is suited for substrate recognition, as revealed by an approximately 50 -fold increase in substrate-binding affinity [25-27, 29]. This is not the only benefit deriving from the phosphorylation of $\mathrm{Thr}^{160}$. The overall rate of phosphotransfer by CDK2-cyclin-A is increased by a stunning $\sim 3,000$-fold when this residue is phosphorylated, suggesting that phosphorylation must also be important for the stabilization of the transition state during phosphotransfer [27, 29]. 


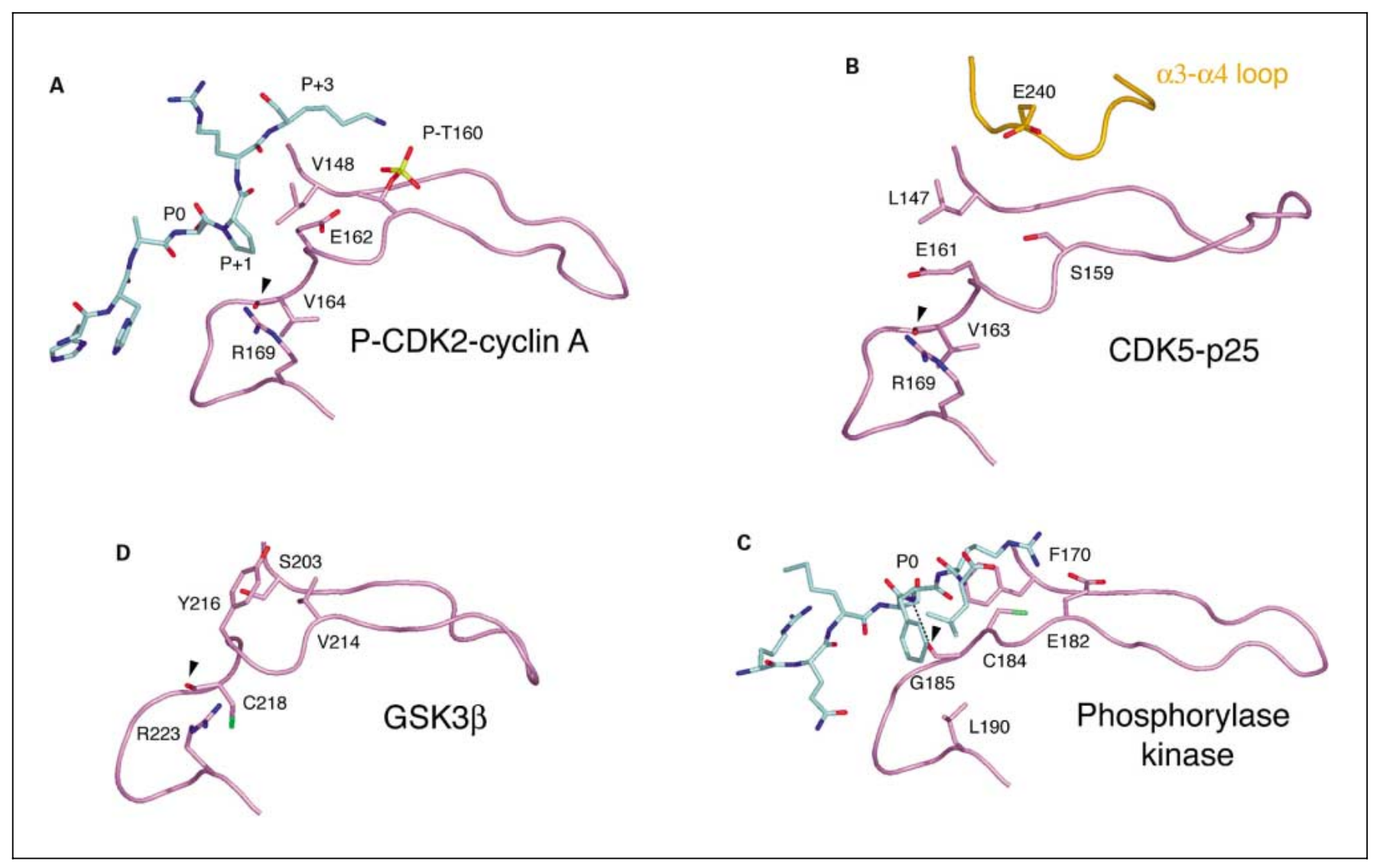

Fig. 2. The activation loop of proline-directed and non-prolinedirected kinases. A Structure of the phospho-CDK2-cyclin-A peptide complex in the region of the activation loop (magenta). The amino acid sequence of the peptide substrate (light blue) is HHASPRK, where $\mathrm{S}$ at the $\mathrm{P}_{0}$ position is the phosphoryl acceptor [26]. CDK2 is proline directed, and the carbonyl group of $\mathrm{Val}^{164}$ adopts an unusual conformation to allow the proline side chain $\left(\mathrm{P}_{+1}\right)$ in the active site. The side chains of Leu ${ }^{148}$, phospho-Thr ${ }^{160}$, Glu ${ }^{162}$ and Arg $^{169}$, which are discussed in the text, are also shown. The black arrowhead indicates the carbonyl group of $\mathrm{Val}^{164}$, which is directed away from the active site; a similar arrowhead is used in the other panels to indicate the equivalent carbonyl group. B The structure of the CDK5 activation loop is identical, but in the absence of phosphorylation [28]. The side chain of $\mathrm{Glu}^{240}$ of p25 in the $\alpha 3-\alpha 4$ loop is shown together with the equivalent residues shown in A. C Structure of the activation loop of phosphorylase kinase with bound peptide [45]. Phosphorylase kinase is not directed by proline. The activation loop adopts an extended conformation, but the carbonyl group of Gly ${ }^{185}$ (black arrowhead) is now used to form a hydrogen bond with the peptide substrate (dashed line). D Structure of the GSK3 $\beta$ activation loop, which is kept in an extended conformation by a priming phosphate [58] which is not shown in the figure. Overall, the structure of the activation loop is very similar to those in $\mathbf{A}$ and $\mathbf{B}$, with the carbonyl of $\mathrm{Cys}^{218}$ pointing away from the active site as in other prolinedirected kinases, but the residues neighboring the proline pocket are different. Figures 1 and 2 were created with program PyMOL [DeLano, W.L.: The PyMOL Molecular Graphics System (2002) on http://www.pymol.org].

\section{p25, p35 and p39 Are One-Step Activators of CDK5}

The structure of the unphosphorylated CDK5-p25 complex [28] confirmed that a cyclin box fold (CBF) is embedded in p25, p35 and p39 (fig. 1), as previously suggested by limited sequence similarity, modeling and threading methods [30-32]. The CBF is the approximately 100-residue structural motif cyclins use to interact with their CDK partners [33]. While cyclin A contains 2 consecutive CBF domains (of which only the first binds CDK2), only a single CBF is found in $\mathrm{p} 25$, and a comparison of $\mathrm{p} 25$ with $\mathrm{p} 35$ and $\mathrm{p} 39$ suggests that all 3 proteins contain a single CBF [28]. Remarkably, there are only 12 identical residues in a structural alignment of the first CBF of human cyclin A with the CBF of human p25, creating some uncertainty on the phylogenetic bases of the structural similarity of these CDK-binding domains [28]. 
The p25 CBF binds CDK5 around the PSAALRE helix and the activation loop. Similar to cyclins, p25 acts on the $\alpha \mathrm{C}$ helix to foster the $\mathrm{Lys}^{33}$-Glu ${ }^{51}$ interaction required to position the ATP moiety, and the overall aspect of the CDK5-p25 complex is very similar to the CDK2-cyclin-A complex [28]. However, a closer inspection reveals important structural and regulatory differences between the CDK5-p25 and CDK2-cyclin-A complexes, some of which impinge directly on the mechanism of CDK5 activation. A first difference concerns the helix that precedes the CBF arrangement in p35 and cyclin A, known as the N-terminal helix $(\alpha \mathrm{NT})$. In the CDK2cyclin-A structure, $\alpha$ NT contacts the kinase moiety directly. A segment encompassing residues $145-173$ of p35, which contains the $\alpha \mathrm{NT}$ helix, has been proposed as a CDK5- and Pctaire1-interacting domain [34, 35]. These in vitro binding data, however, are incompatible with the structure of the CDK5-p25 complex, which showed that this segment is not in a direct contact with CDK5 and rather packs against the CBF of p25 opposite the CDK5binding site [28]. A second and more relevant difference is that even in the absence of a phosphate group on Ser ${ }^{159}$ the CDK5 activation loop adopts an extended conformation typical of active proline-directed kinases (fig. 2). This conformation is almost identical to that observed in the phospho-CDK2-cyclin-A complex, establishing that p25 acts as a one-step activator of CDK5, whose binding to CDK5 introduces in a single step the conformational changes CDK2 undergoes via 2 independent regulatory events such as cyclin A binding and $\mathrm{Thr}^{160}$ phosphorylation. Phospho-Thr ${ }^{160}$ of CDK2 acts as an organizing center that interacts with 3 neighboring arginine residues $\left(\mathrm{Arg}^{50}, \operatorname{Arg}^{126}\right.$ and $\left.\operatorname{Arg}^{150}\right)$, stabilizing the active, extended conformation of the loop [25, 26]. In the CDK5-p25 complex, the structural requirement for phosphorylation is bypassed by an extensive network of interactions that $\mathrm{p} 25$ establishes with the CDK5 activation loop - a feature that is not observed in the phospho-CDK2-cyclin-A complex. Besides $\mathrm{Arg}^{50}$, whose side chain adopts a different rotamer, $\operatorname{Arg}^{126}$ and $\operatorname{Arg}^{150}$ of CDK5 occupy the same positions of their CDK2 counterparts, but there is no obvious mechanism of charge compensation in the CDK5-p25 complex [28].

A prediction from these results is that activation loop phosphorylation at $\operatorname{Ser}^{159}$ is not required to activate CDK5. Although it has been proposed that an activity exists in PC12 cells, which phosphorylates $\operatorname{Ser}^{159}$ and activates CDK5 [36], there is solid evidence that CDK5 is not phosphorylated on $\operatorname{Ser}^{159}$, and that phosphorylation of this residue is not required for kinase activity of the
CDK5-p35 complex [22, 28, 37, 38]. If occurring, phosphorylation of $\operatorname{Ser}^{159}$ may even have an inhibitory effect on the CDK5-p35 interaction. This is suggested by the fact that substituting Ser ${ }^{159}$ with glutamic acid impairs the interaction of CDK5 with p35, and even the apparently conservative substitution of $\mathrm{Ser}^{159}$ into threonine causes a significant loss in p35-binding ability [28], an effect due to steric hindrance at the very tight interface between the activation loop of CDK5 and p25 [28].

\section{What Drives Specificity of CDK5 Binding by p35 or p39?}

Thus, the presence of serine rather than threonine on the CDK5 activation loop may be important for the CDK5-p35 interaction (and likely also for the related interaction with p39). Because threonine, rather than serine, is encountered in all other CDK family members, it is interesting to ask if this is what makes the CDK5p35 interaction so selective [37]. Although Thr ${ }^{159}$-CDK5 is severely impaired in p 35 binding, the substitution of Thr ${ }^{160}$ with serine in CDK2 did not turn CDK2 into a p35-binding protein [Rani Dhavan and Li-Huei Tsai, pers. commun.], indicating that other mechanisms may also prevent the interaction of $\mathrm{p} 35$ by CDK2. Recently, it has been found that Pctaire1, another CDK family member, interacts with p35 in vitro and in cultured myotubes and skeletal muscle [34]. The significance of this interaction is elusive, because Pctaire1 may not require an activating subunit [39]. Furthermore, a previous study had suggested that the binding affinity of Pctaire1 for p35 might be significantly lower than that for CDK5 [37].

Because the substitution of $\operatorname{Ser}^{159}$ with alanine does not seem to alter the specific activity of the CDK5-p35 complex $[22,28,37,38]$, the presence of a phosphate acceptor residue such as serine at this position may not be relevant at all. It cannot be ruled out of course that a modification of this residue becomes important upon incorporation of CDK5 in complexes other than those it forms with $\mathrm{p} 35$ or p39. We have already mentioned CDK5 complexes with cyclins $\mathrm{D}$ and $\mathrm{E}$, which are devoid of activity. It has also been reported that upon its heterologous expression in budding yeast, CDK 5 binds to and is activated by Pho 80 and Pcl2, 2 proteins normally acting as activators of the Pho85 kinase [38, 40]. Pho85 is regarded as the budding yeast CDK5 orthologue [12, 41]. How Pho80 and Pcl2 activate CDK5 is unclear, but phosphorylation of $\operatorname{Ser}^{159}$ is unlikely to be required, because the natural partner of 
Pho80 and Pcl2, Pho85, does not appear to require phosphorylation on the equivalent residue $\operatorname{Ser}^{166}$ or more generally on the activation loop [38, 40, 41].

CDK5 also forms a complex with Cables, a ligand and a substrate of the Abl tyrosine kinase, and a CBF-containing protein that binds CDK 5 competitively with $\mathrm{p} 35 / \mathrm{p} 39$ [42]. Although Cables contains a bona-fide CBF and is capable of entering a tight binary complex with CDK5 in vitro, there is no evidence that the CDK5-Cables complex is active or that it can be made active by phosphorylation [M.M. and A.M., unpubl. results]. It has been suggested that Cables may regulate the phosphorylation of CDK5 on $\mathrm{Tyr}^{15}$ by the Abl or Fyn tyrosine kinases, which would in turn lead to the activation of the CDK5-p35 complex $[42,43]$. Phosphorylation of $\mathrm{Thr}^{14}$ and $\mathrm{Tyr}^{15}$ in the glycine-rich loop, the 'ceiling' of the ATP-binding site, is an important element of CDK regulation [14], whose structural bases remain largely unclear because the flexibility of the glycine-rich loop complicates direct structural investigations. Phosphorylation of $\mathrm{Tyr}^{15}$ by the Wee1 kinase negatively regulates CDK1 activity and is a master switch in the control of the $\mathrm{G}_{2}-\mathrm{M}$ transition of the cell cycle [14]. In vitro, CDK5 is phosphorylated on $\mathrm{Thr}^{14}$ and inhibited by an unidentified kinase activity, but the significance of $\mathrm{Thr}^{14}$ in vivo remains uncertain [44]. $\mathrm{Tyr}^{15}$ phosphorylation of CDK5, on the other hand, occurs both in vitro and in vivo $[42,43]$. The CDK5-p35 complex is not regulated or phosphorylated by the Weel kinase in vitro [37]. Tyr ${ }^{15}$ of CDK5, however, appears to be a target of nonreceptor tyrosine kinases such as Abl and Fyn [42, 43]. Although $\mathrm{Tyr}^{15}$ phosphorylation regulates CDK1 negatively, it seems to upregulate the kinase activity of CDK5-p35 towards histone $\mathrm{H}_{1}$ or a histone $\mathrm{H}_{1}$ peptide substrate [42, 43]. We failed to observe an increase in the activity of the CDK5-p25 complex by Abl-mediated Tyr ${ }^{15}$ phosphorylation using purified components, and a light but consistent repression was observed instead [M.M and A.M., unpubl. results]. On the other hand, the basal level of histone $\mathrm{H}_{1}$ phosphorylation by CDK5-Cables is almost negligible if compared with CDK5-p25 and is not significantly upregulated by $\mathrm{Tyr}^{15}$ phosphorylation [M.M and A.M., unpubl. results].

\section{Substrate Recognition}

Difficulties in co-crystallizing kinases with their substrates has also limited the availability of structures of kinase-substrate complexes, of which only a few are available [26, 45-48]. Although a structure of the CDK5-p25 complex in the presence of a CDK5 substrate is not available at this time, the structure of phospho-CDK2-cyclin-A bound to ATP and to a proline-containing substrate peptide has been reported [26], providing a very useful tool to understand how phosphorylation of $\mathrm{Thr}^{160}$ influences activation and substrate recognition by proline-directed kinases [49-55]. How is this specificity built? To answer this question, it is critical to understand that the activation loop acts as a platform to align the kinase substrate for phosphotransfer, playing an essential role in substrate recognition (fig. 2). Phosphorylation of $\mathrm{Thr}^{160}$ in CDK2 restructures the activation loop, promoting the rotation of the carbonyl group of $\mathrm{Val}^{164}$ away from the active site and creating a binding pocket for the proline in the $\mathrm{P}_{+1}$ position of the substrate. The main chain phi angle for $\mathrm{Val}^{164}$ (approx. $+72^{\circ}$ ) is typical of a left-handed helix, and the main chain conformation of this residue is stabilized by hydrogen bonds involving the main chain of $\operatorname{Arg}^{126}$ and the side chain of $\operatorname{Arg}^{169}[25,26]$.

These features are utterly conserved in the structures of unphosphorylated (but active) CDK5-p25 and of the doubly phosphorylated (and also active) ERK2, another proline-directed kinase [28, 56]. $\mathrm{Val}^{163}$ of CDK5 and $\mathrm{Ala}^{187}$ of ERK2 adopt the same main chain conformation of Val ${ }^{164}$ of CDK2 (phi angles around $70-80^{\circ}$ ). Similarity in the active conformation of 3 proline-directed kinases has 2 implications. First, it predicts that substrates bind across the active sites of CDK5 and ERK2 with the same orientation observed in CDK2, which is opposite to that previously proposed by a modeling study [57]. The second implication is that the conformation of the activation loop around $\mathrm{Val}^{164}$ (CDK2 numbering) in active kinases is specifically designed for the recognition of the $\mathrm{P}_{+1}$ proline (for a more complete discussion on why this main chain conformation may be tailored for the recognition of proline, see Brown et al. [26]). What is the predictive value of this observation? The conformation of the activation loop of active GSK $3 \beta$, another proline-directed kinase, is once again essentially indistinguishable from that of CDK2, with $\mathrm{Cys}^{218}$ (equivalent to $\mathrm{Val}^{164}$ of CDK2) adopting a phi angle of $82^{\circ}$ [58]. Although GSK3 $\beta$ is defined a prolinedirected kinase, its preference for proline at the $\mathrm{P}_{+1}$ position is milder than for CDKs or ERK2 [58, 59]. This suggests that other residues around $\mathrm{Val}^{164}$ are likely to contribute to the recognition of proline at the $\mathrm{P}_{+1}$ position, conferring stronger or weaker discriminatory capacity. Two candidates for this function are $\mathrm{Leu}^{148}$ and $\mathrm{Glu}^{162}$ (CDK2 numbering), 2 residues that are shown to be in van der Waals contact with the $\mathrm{P}_{+1}$ proline in the 
phospho-CDK2-cyclin-A-peptide complex structure [26]. $\mathrm{Leu}^{148}$ and Glu ${ }^{162}$ are conserved in CDK2, CDK5 and ERK2, but are mutated in GSK3 $\beta$.

The structural comparison of CDK5-p25 with phospho-CDK2-cyclin-A also suggests differences in the substrate-binding mechanism. Phospho-Thr ${ }^{160}-\mathrm{CDK} 2$, for instance, uses the phosphate group of $\mathrm{Thr}^{160}$ to select substrates containing a positively charged residue at the $\mathrm{P}_{+3}$ position relative to the Ser/Thr phosphate acceptor [26]. Interestingly, CDK5 also shows a preference for positively charged residues at the $\mathrm{P}_{+3}$ position, and to a lesser extent also at the $\mathrm{P}_{+2}$ and $\mathrm{P}_{+4}$ positions, despite its lack of phosphorylation on $\operatorname{Ser}^{159}[50,51,55,60]$. It has been proposed that $\mathrm{Glu}^{240}$ of p 25 directs unphosphorylated CDK 5 to positively charged substrates (fig. 2), playing vicariously an equivalent function to that of phospho- $\mathrm{T}^{160}$ of CDK2 [28]. Further differences in recognition mode between CDK 2 and CDK5 are expected because the architecture of the substrate-binding region in the CDK5-p25 complex is very different from that observed for CDK2cyclin-A. This is due to the close proximity of the p25 $\alpha 3-$ $\alpha 4$ loop to the activation loop of CDK5, which raises the expectation that the $\mathrm{p} 25$ subunit may deeply influence the interaction of CDK5 with its substrates [28]. The fact that cyclins influence the substrate specificity of the CDKs to which they bind has been known for some time. Cyclins contain a binding surface that interacts with a docking motif (ZRXL in single-letter amino acid code, where Z and $X$ are usually basic residues) that in several CDK substrates neighbors the phosphate acceptor site [13]. This motif is also present in the cell cycle inhibitor p27 [61]. Consistent with the structural and functional differences between cyclin A and p35, it has been found that p35 allows CDK 5 to escape inhibition by p 27 [62], and motifs conforming to the ZRXL consensus have not been identified yet in CDK5 substrates. Alternative motifs mediating the interaction of CDK5 substrates with $\mathrm{p} 35$ have not yet been identified either but are expected to exist, as explained above. A protein that binds $\mathrm{p} 35$ and inhibits the activity of CDK 5 has been identified recently [63]. This protein may be a functional homologue of $\mathrm{p} 27$, but its precise mechanism of p35 binding and CDK5 inhibition remains unclear.

\section{The Deregulation of CDK5 Activity}

p35 and p39 share a similar organization, with an Nterminal approximately 100 -residue segment that is probably disordered and a C-terminal domain expected to be identical to the p25 domain revealed by the CDK5-p25 crystal structure [28]. p25 is generated when neurotoxic insults cause the calpain-mediated cleavage of the p35 activators. An equivalent p29 segment is generated under similar conditions from the p39 activator [64-68]. p25 and p29 contain the CBF regions of p35 and p39 and therefore retain the ability to interact and activate CDK5 [69]. The p25 and p29 polypeptides have an increased half-life relative to the parent proteins. Their accumulation in CDK5 complexes is very toxic for neurons [6468]. p35 and p39 are modified by the addition of a myristyl group at their $\mathrm{N}$ terminus, a modification that may direct the p35/p39-CDK5 complexes to cellular membranes. Mislocalization of active CDK5 upon p25 and p29 accumulation results in nonphysiological phosphorylation of certain substrates and has been proposed as the cause of CDK5 deregulation and of its effects on neurodegeneration [69]. Recent unexpected results with the Abl kinase have revealed the existence of a conformational switch controlled by the interaction with an N-terminal myristoyl group, which regulates the activity of $\mathrm{Abl}[70$, 71]. Does a myristoyl switch regulate the CDK5-p35/p39 complexes? This hypothesis may provide an alternative or parallel explanation for the deregulation of CDK5. Upon p35/p39 cleavage, the CDK5-p25/p29 moieties would be parted from the myristoylated $\mathrm{N}$-terminal segments of the p35/p39 activators and hence deregulated.

\section{Conclusions}

The structural bases of CDK5 regulation have remained mysterious until the determination of the threedimensional structure of CDK5-p25 provided a framework to understand many of its unusual features [28]. The development of pharmacological tools to inhibit CDK5 and other CDK family members potently and selectively has become the inspiring target for the cure of several human diseases in which the activity of these proteins is deregulated [72]. A growing understanding of the structural bases of kinase activation has propelled new approaches to interfere with kinase function, with the most striking example being the identification of Gleevec as an Abl kinase inhibitor and a pharmacological agent in the cure of chronic myelogenous leukemia [73]. The general principle brought about by the mechanism of inhibition exerted by Gleevec on Abl is that specificity might be achieved by targeting the inactive conformation of a given kinase, as this is more distinctive than the active state [74]. The challenge for the future is to create similar inhib- 
itory tools for all those kinases that are identified as promising candidates for pharmacological intervention. The availability of a structure of the CDK5-p25 complex represents a new step in this direction.

\section{Acknowledgments}

We would like to thank the Alzheimer's Association, the Telethon Foundation and the Italian Association for Cancer Research for generous funding. A.M. is a Scholar of the Italian Foundation for Cancer Research and an EMBO Young Investigator. M.M. is a Fellow of the Italian Foundation for Cancer Research. We apologize to all those researchers whose work was not cited in this review due to space limitations.

\section{References}

1 Meyerson M, Enders GH, Wu CL, Su LK, Gorka C, Nelson C, Harlow E, Tsai LH: A family of human cdc2-related protein kinases. Embo J 1992;11:2909.

2 Huse M, Kuriyan J: The conformational plasticity of protein kinases. Cell 2002;109:275.

3 Johnson, LN, Noble ME, Owen DJ: Active and inactive protein kinases: Structural basis for regulation. Cell 1996:85:149.

4 Buzko O, Shokat KM: A kinase sequence database: Sequence alignments and family assignment. Bioinformatics 2002;18:1274.

5 Rubin GM, Yandell MD, Wortman JR, Gabor Miklos GL, Nelson CR, Hariharan IK, Fortini ME, Li PW, Apweiler R, Fleischmann W, Cherry JM, Henikoff S, Skupski MP, Misra S, Ashburner M, Birney E, Boguski MS, Brody T, Brokstein P, Celniker SE, Chervitz SA, Coates D, Cravchik A, Gabrielian A, Galle RF, Gelbart WM, George RA, Goldstein LS, Gong F, Guan P, Harris NL, Hay BA, Hoskins RA, Li J, Li Z, Hynes RO, Jones SJ, Kuehl PM, Lemaitre B, Littleton JT, Morrison DK, Mungall C, O'Farrell PH, Pickeral OK, Shue C, Vosshall LB, Zhang J, Zhao Q, Zheng XH, Zhong F, Zhong W, Gibbs R, Venter JC, Adams MD, Lewis S: Comparative genomics of the eukaryotes. Science 2000;287:2204.

6 Manning G, Whyte DB, Martinez R, Hunter T, Sudarsanam S: The protein kinase complement of the human genome. Science 2002:298:1912.

7 Knighton DR, Zheng JH, Ten Eyck LF, Ashford VA, Xuong NH, Taylor SS, Sowadski JM: Crystal structure of the catalytic subunit of cyclic adenosine monophosphate-dependent protein kinase. Science 1991;253:407.

8 Pavletich NP: Mechanisms of cyclin-dependent kinase regulation: Structures of CDKs, their cyclin activators, and Cip and INK4 inhibitors. J Mol Biol 1999;287:821.

9 Adams JA: Activation loop phosphorylation and catalysis in protein kinases: Is there functional evidence for the autoinhibitor model? Biochemistry 2003;42:601.

10 Schulze-Gahmen U, De Bondt HL, Kim SH: High-resolution crystal structures of human cyclin-dependent kinase 2 with and without ATP Bound waters and natural ligand as guides for inhibitor design. J Med Chem 1996:39:4540.

11 De Bondt HL, Rosenblatt J, Jancarik J, Jones HD, Morgan DO, Kim SH: Crystal structure of cyclin-dependent kinase 2. Nature 1993;363: 595.
12 Liu J, Kipreos ET: Evolution of cyclin-dependent kinases (CDKs) and CDK-activating kinases (CAKs): Differential conservation of CAKs in yeast and metazoa. Mol Biol Evol 2000; $17: 1061$

13 Endicott JA, Noble ME, Tucker JA: Cyclindependent kinases: Inhibition and substrate recognition. Curr Opin Struct Biol 1999:9:738.

14 Morgan DO: Principles of CDK regulation. Nature 1995:374:131.

15 Obaya AJ, Sedivy JM: Regulation of cyclinCdk activity in mammalian cells. Cell Mol Life Sci 2002;59:126.

16 Xiong Y, Zhang H, Beach D: D type cyclins associate with multiple protein kinases and the NA replication and repair factor PCNA. Cell 1992;71:505.

17 Miyajima M, Nornes HO, Neuman T: Cyclin E is expressed in neurons and forms complexes with cdk5. Neuroreport 1995;6:1130.

18 Lew J, Huang QQ, Qi Z, Winkfein RJ, Aebersold R, Hunt T, Wang JH: A brain-specific activator of cyclin-dependent kinase 5. Nature 1994:371:423.

19 Tsai LH, Delalle I, Caviness VS Jr, Chae T, Harlow E: p35 is a neural-specific regulatory subunit of cyclin-dependent kinase 5. Nature 1994;371:419.

20 Ishiguro K, Kobayashi S, Omori A, Takamatsu M, Yonekura S, Anzai K, Imahori K, Uchida $\mathrm{T}$ : Identification of the $23 \mathrm{kDa}$ subunit of tau protein kinase II as a putative activator of cdk5 in bovine brain. FEBS Lett 1994;342:203.

21 Uchida T, Ishiguro K, Ohnuma J, Takamatsu M, Yonekura S, Imahori K: Precursor of cdk5 activator, the $23 \mathrm{kDa}$ subunit of tau protein kinase II: Its sequence and developmental change in brain. FEBS Lett 1994;355:35.

22 Qi Z, Huang QQ, Lee KY, Lew J, Wang JH: Reconstitution of neuronal Cdc2-like kinase from bacteria-expressed Cdk5 and an active fragment of the brain-specific activator: Kinase activation in the absence of $\mathrm{Cdk} 5$ phosphorylation. J Biol Chem 1995;270:10847.

23 Jeffrey PD, Russo AA, Polyak K, Gibbs E, Hurwitz J, Massague J, Pavletich NP: Mechanism of CDK activation revealed by the structure of a cyclinA-CDK2 complex. Nature 1995; $376: 313$
24 Brown NR, Noble ME, Lawrie AM, Morris MC, Tunnah P, Divita G, Johnson LN, Endicott JA: Effects of phosphorylation of threonine 160 on cyclin-dependent kinase 2 structure and activity. J Biol Chem 1999:274:8746.

25 Russo AA, Jeffrey PD, Pavletich NP: Structural basis of cyclin-dependent kinase activation by phosphorylation. Nat Struct Biol 1996:3: 696.

26 Brown NR, Noble ME, Endicott JA, Johnson LN: The structural basis for specificity of substrate and recruitment peptides for cyclin-dependent kinases. Nat Cell Biol 1999;1:438.

27 Lew J: MAP kinases and CDKs: Kinetic basis for catalytic activation. Biochemistry 2003;42: 849.

28 Tarricone C, Dhavan R, Peng J, Areces LB, Tsai L, Musacchio A: Structure and regulation of the cdk5-p25(nck5a) complex. Mol Cell 2001;8:657.

29 Hagopian JC, Kirtley MP, Stevenson LM, Gergis RM, Russo AA, Pavletich NP, Parsons SM, Lew J: Kinetic basis for activation of CDK2/ cyclin A by phosphorylation. J Biol Chem 2001;276:275.

30 Brown NR, Noble ME, Endicott JA, Garman EF, Wakatsuki S, Mitchell E, Rasmussen B, Hunt T, Johnson LN: The crystal structure of cyclin A. Structure 1995;3:1235.

31 Tang D, Chun ACS, Zhang M, Wang JH: $\mathrm{Cy}$ clin-dependent kinase 5 (Cdk5) activation domain of neuronal Cdk5 activator: Evidence of the existence of cyclin fold in neuronal Cdk5a activator. J Biol Chem 1997;272:12318.

32 Chou KC, Watenpaugh KD, Heinrikson RL: A model of the complex between cyclin-dependent kinase 5 and the activation domain of neuronal Cdk5 activator. Biochem Biophys Res Commun 1999:259:420.

33 Gibson TJ, Thompson JD, Blocker A, Kouzarides T: Evidence for a protein domain superfamily shared by the cyclins, TFIIB and RB/ p107. Nucleic Acids Res 1994;22:946.

34 Cheng K, Li Z, Fu W-Y, Wang JH, Fu AKY, Ip NY: Pctaire1 interacts with $\mathrm{p} 35$ and is a novel substrate for Cdk5/p35. J Biol Chem 2002;277: 31988-31993.

35 Chin KT, Ohki SY, Tang D, Cheng HC, Wang $\mathrm{JH}$, Zhang M: Identification and structure characterization of a Cdk inhibitory peptide derived from neuronal-specific Cdk5 activator. J Biol Chem 1999;274:7120. 
36 Sharma P, Sharma M, Amin ND, Albers RW, Pant HC: Regulation of cyclin-dependent kinase 5 catalytic activity by phosphorylation. Proc Natl Acad Sci USA 1999;96:11156.

37 Poon RY, Lew J, Hunter T: Identification of functional domains in the neuronal Cdk5 activator protein. J Biol Chem 1997;272:5703.

38 Nishizawa M, Kanaya Y, Toh EA: Mouse cyclin-dependent kinase $(\mathrm{Cdk}) 5$ is a functional homologue of a yeast Cdk, pho85 kinase. J Biol Chem 1999;274:33859.

39 Graeser R, Gannon J, Poon RYC, Dubois T, Aitken A, Hunt T: Regulation of the CDKrelated protein kinase PCTAIRE-1 and its possible role in neurite outgrowth in Neuro-2A cells. J Cell Sci 2002;1 15:3479.

40 Huang D, Patrick G, Moffat J, Tsai LH, Andrews B: Mammalian Cdk5 is a functional homologue of the budding yeast Pho85 cyclindependent protein kinase. Proc Natl Acad Sci USA 1999; 96:14445.

41 Toh EA, Nishizawa M: Structure and function of cyclin-dependent Pho85 kinase of Saccharomyces cerevisiae. J Gen Appl Microbiol 2001; 47:107.

42 Zukerberg LR, Patrick GN, Nikolic M, Humbert S, Wu CL, Lanier LM, Gertler FB, Vidal M, Van Etten RA, Tsai LH: Cables links Cdk5 and c-Abl and facilitates Cdk5 tyrosine phosphorylation, kinase upregulation, and neurite outgrowth. Neuron 2000;26:633.

43 Sasaki Y, Cheng C, Uchida Y, Nakajima O, Ohshima T, Yagi T, Taniguchi M, Nakayama T, Kishida R, Kudo Y, Ohno S, Nakamura F, Goshima Y: Fyn and Cdk5 mediate semaphorin-3A signaling, which is involved in regulation of dendrite orientation in cerebral cortex Neuron 2002;35:907.

44 Matsuura I, Wang JH: Demonstration of cyclin-dependent kinase inhibitory serine/threonine kinase in bovine thymus. J Biol Chem 1996;271:5443.

45 Lowe ED, Noble MEM, Skamnaki VT, Oikonomakos NG, Owen DJ, Johnson LN: The crystal structure of a phosphorylase kinase peptide substrate complex: Kinase substrate recognition. EMBO J 1997; 16:6646.

46 Bossemeyer D, Engh RA, Kinzel V, Ponsting $\mathrm{H}$, Huber R: Phosphotransferase and substrate binding mechanism of the cAMP-dependent protein kinase catalytic subunit from porcine heart as deduced from the $2.0 \mathrm{~A}$ structure of the complex with $\mathrm{Mn}^{2+}$ adenylyl imidodiphosphate and inhibitor peptide PKI(5-24). EMBO J 1993; 12:849.

47 Yang J, Cron P, Good VM, Thompson V, Hemmings BA, Barford D: Crystal structure of an activated Akt/protein kinase B ternary complex with GSK3-peptide and AMP-PNP. Nat Struct Biol 2002;9:940.
48 Zheng J, Knighton DR, ten Eyck LF, Karlsson R, Xuong N, Taylor SS, Sowadski JM: Crystal structure of the catalytic subunit of cAMPdependent protein kinase complexed with MgATP and peptide inhibitor. Biochemistry 1993;32:2154.

49 Songyang Z, Blechner S, Hoagland N, Hoekstra MF, Piwnica-Worms H, Cantley LC: Use of an oriented peptide library to determine the optimal substrates of protein kinases. Curr Biol 1994:4:973.

50 Songyang Z, Lu KP, Kwon YT, Tsai LH, Filhol O, Cochet C, Brickey DA, Soderling TR, Bartleson C, Graves DJ, De Maggio AJ, Hoekstra MF, Blenis J, Hunter T, Cantley LC: A structural basis for substrate specificities of protein Ser/Thr kinases: Primary sequence preference of casein kinases I and II, NIMA, phosphorylase kinase, calmodulin-dependent kinase II, CDK5, and Erk1. Mol Cell Biol 1996;16:6486.

51 Sharma P, Barchi JJ Jr, Huang X, Amin ND, Jaffe H, Pant HC: Site-specific phosphorylation of Lys-Ser-Pro repeat peptides from neurofilament $\mathrm{H}$ by cyclin-dependent kinase 5 : Structural basis for substrate recognition. Biochemistry 1998:37:4759.

52 Holmes JK, Solomon MJ: A predictive scale for evaluating cyclin-dependent kinase substrates: A comparison of $\mathrm{p} 34 \mathrm{cdc} 2$ and $\mathrm{p} 33 \mathrm{cdk} 2$. J Biol Chem 1996;271:25240.

53 Kitagawa M, Higashi H, Jung HK, SuzukiTakahashi I, Ikeda M, Tamai K, Kato J, Segawa K, Yoshida E, Nishimura S, Taya Y: The consensus motif for phosphorylation by cyclin D1-Cdk4 is different from that for phosphorylation by cyclin A/E-Cdk2. EMBO J 1996;15: 7060 .

54 Higashi H, Suzuki-Takahashi I, Taya Y, Segawa K, Nishimura S, Kitagawa M: Differences in substrate specificity between Cdk2-cyclin A and Cdk2-cyclin E in vitro. Biochem Biophys Res Commun 1995;216:520.

55 Shetty KT, Link WT, Pant HC: cdc2-like kinase from rat spinal cord specifically phosphorylates KSPXK motifs in neurofilament proteins: Isolation and characterization. Proc Natl Acad Sci USA 1993;90:6844.

56 Canagarajah BJ, Khokhlatchev A, Cobb MH, Goldsmith EJ: Activation mechanism of the MAP kinase ERK2 by dual phosphorylation. Cell 1997;90:859.

57 Sharma P, Steinbach PJ, Sharma M, Amin ND, Barchi JJ Jr, Pant HC: Identification of substrate binding site of cyclin-dependent kinase 5. J Biol Chem 1999;274:9600.

58 Dajani R, Fraser E, Roe SM, Young N, Good V, Dale TC, Pearl LH: Crystal structure of glycogen synthase kinase 3 beta: Structural basis for phosphate-primed substrate specificity and autoinhibition. Cell 2001;105:721.

59 Cohen P, Frame S: The renaissance of GSK3. Nat Rev Mol Cell Biol 2001;2:769.
60 Beaudette KN, Lew J, Wang JH: Substrate specificity characterization of a cdc2-like protein kinase purified from bovine brain. J Biol Chem 1993;268:20825.

61 Russo AA, Jeffrey PD, Patten AK, Massague J, Pavletich NP: Crystal structure of the p27Kip1 cyclin-dependent-kinase inhibitor bound to the cyclin A-Cdk2 complex. Nature 1996;382:325.

62 Lee MH, Nikolic M, Baptista CA, Lai E, Tsai LH, Massague J: The brain-specific activator p35 allows Cdk5 to escape inhibition by p27Kip1 in neurons. Proc Natl Acad Sci USA 1996;93:3259.

63 Ching YP, Pang AS, Lam WH, Qi RZ, Wang JH: Identification of a neuronal Cdk5 activator-binding protein as $\mathrm{Cdk} 5$ inhibitor. $\mathrm{J}$ Biol Chem 2002;277:15237.

64 Patrick GN, Zukerberg L, Nikolic M, de la Monte S, Dikkes P, Tsai LH: Conversion of p35 to p25 deregulates Cdk5 activity and promotes neurodegeneration. Nature 1999;402: 615.

65 Lee MS, Kwon YT, Li M, Peng J, Friedlander RM, Tsai LH: Neurotoxicity induces cleavage of p35 to p25 by calpain. Nature 2000;405: 360.

66 Kusakawa G, Saito T, Onuki R, Ishiguro K, Kishimoto T, Hisanaga S: Calpain-dependent proteolytic cleavage of the p35 cyclin-dependent kinase 5 activator to p25. J Biol Chem 2000;275:17166.

67 Nath R, Davis M, Probert AW, Kupina NC, Ren X, Schielke GP, Wang KK: Processing of cdk5 activator $\mathrm{p} 35$ to its truncated form (p25) by calpain in acutely injured neuronal cells. Biochem Biophys Res Commun 2000;274:16.

68 Patzke H, Tsai LH: Calpain-mediated cleavage of the cyclin-dependent kinase-5 activator p39 to p29. J Biol Chem 2002:277:8054.

69 Dhavan R, Tsai LH: A decade of cdk5. Nat Rev Mol Cell Biol 2001;2:749.

70 Hantschel O, Nagar B, Guettler S, Kretzschmar J, Dorey K, Kuriyan J: Superti-Furga, G: A myristoyl/phosphotyrosine switch regulates cAbl. Cell 2003;112:845.

71 Nagar B, Hantschel O, Young MA, Scheffzek K, Veach D, Bornmann W, Clarkson B, Superti-Furga G, Kuriyan J: Structural basis for the autoinhibition of c-Abl tyrosine kinase. Cell 2003; $112: 859$.

72 Knockaert M, Greengard P, Meijer L: Pharmacological inhibitors of cyclin-dependent kinases. Trends Pharmacol Sci 2002;23:417.

73 Capdeville R, Buchdunger E, Zimmermann J, Matter A: Glivec (STI571, imatinib), a rationally developed, targeted anticancer drug. Nat Rev Drug Discov 2002;1:493.

74 Schindler T, Bornmann W, Pellicena P, Miller WT, Clarkson B, Kuriyan J: Structural mechanism for STI-571 inhibition of Abelson tyrosine kinase. Science 2000;289:1938. 